\title{
Assessment of the Impact of Metropolitan-Scale Urban Planning Scenarios on the Moist Thermal Environment under Global Warming: A Study of the Tokyo Metropolitan Area Using Regional Climate Modeling
}

\author{
Asuka Suzuki-Parker, ${ }^{1}$ Hiroyuki Kusaka, ${ }^{2}$ and Yoshiki Yamagata ${ }^{3}$ \\ ${ }^{1}$ Graduate School of Life and Environmental Sciences, University of Tsukuba, 1-1-1 Tennodai, Tsukuba, Ibaraki 305-8572, Japan \\ ${ }^{2}$ Center for Computational Sciences, University of Tsukuba, Tsukuba, Japan \\ ${ }^{3}$ National Institute for Environmental Studies, Tsukuba, Japan \\ Correspondence should be addressed to Asuka Suzuki-Parker; suzuki.asuka.fp@u.tsukuba.ac.jp
}

Received 3 March 2015; Revised 5 May 2015; Accepted 6 May 2015

Academic Editor: Guillermo Baigorria

Copyright (C) 2015 Asuka Suzuki-Parker et al. This is an open access article distributed under the Creative Commons Attribution License, which permits unrestricted use, distribution, and reproduction in any medium, provided the original work is properly cited.

\begin{abstract}
Using a high-resolution regional climate model coupled with urban canopy model, the present study provides the first attempt in quantifying the impact of metropolitan-scale urban planning scenarios on moist thermal environment under global warming. Tokyo metropolitan area is selected as a test case. Three urban planning scenarios are considered: status quo, dispersed city, and compact city. Their impact on the moist thermal environment is assessed using wet-bulb globe temperature (WBGT). Future projections for the 2070 s show a $2-4^{\circ} \mathrm{C}$ increase in daytime mean WBGT relative to the current climate. The urban scenario impacts are shown to be small, with a -0.4 to $+0.4^{\circ} \mathrm{C}$ range. Relative changes in temperature and humidity as the result of a given urban scenario are shown to be critical in determining the sign of the WBGT changes; however, such changes are not necessarily determined by local changes in urban land surface parameters. These findings indicate that urban land surface changes may improve or worsen the local moist thermal environment and that metropolitan-scale urban planning is inefficient in mitigating heat-related health risks for mature cities like Tokyo.
\end{abstract}

\section{Introduction}

The climate in urbanized areas around the world has undergone substantial change over recent years, with a general trend toward degradation of the thermal environment due to the combined effect of global warming and urbanization. Observational studies indicate that urbanized areas have experienced larger temperature increasing rates than their surrounding rural areas. This trend is reported in multiple urbanized areas around the world, including the United States [1], southeastern China [2], and Japan [3, 4]. Today more than half of the world's population is residing in urbanized areas and this proportion is expected to grow in the future [5]. In addition to the expected further warming of the planet due to anthropogenic greenhouse gas emission [6], urbanization is therefore considered a significant factor for the increased climate-related health risk due to excess heat exposure [7].

These observed and expected changes in urbanized areas have motivated climate scientists to examine the combined impact of urbanization and climate change to urban thermal environment. High-resolution regional climate models (RCMs) are excellent tools in this endeavor, especially when coupled with urban canopy scheme (UCM) $[8,9]$. Using a UCM coupled RCM, Georgescu et al. and Adachi et al. examined the impact of urban expansion under the future climate for Arizona and Tokyo, respectively [10, 11]. A resent work by Argüeso et al. also examined the impact of urban expansion of Sydney using a UCM coupled RCM [12]. While these studies assumed simple urban expansion, impacts of alternative urban scenarios have been developed and tested 


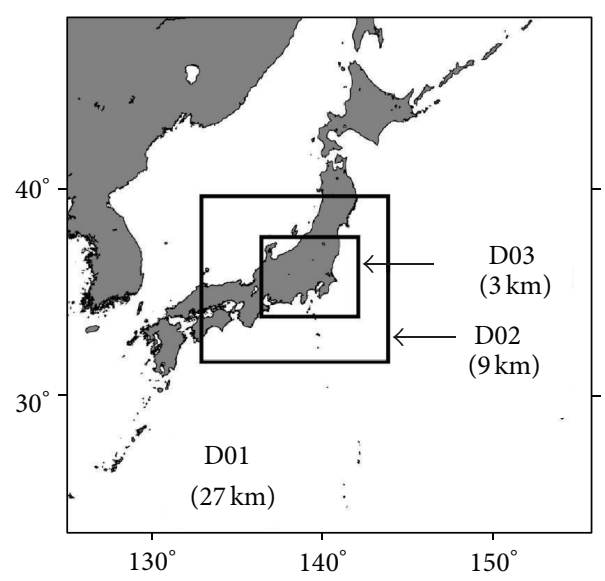

(a)

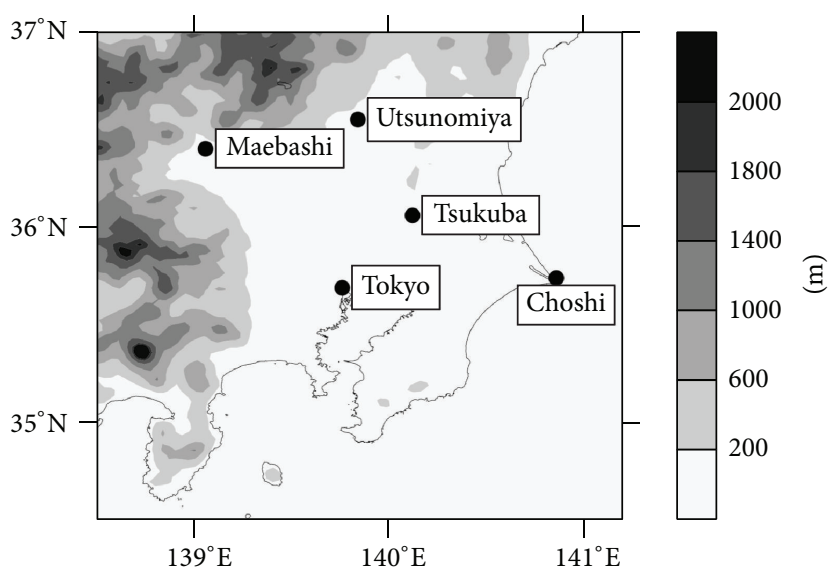

(b)

Figure 1: (a) Model domain setting with three nested domains. (b) Topography of analysis domain and locations and names of the meteorological observation stations used for WBGT.

using RCMs. For example, Shin and Baigorria examined the impact of future alternative urban planning for Central Florida [13], and Ke et al. examined three urban planning scenarios for Wuhan, China [14]. For the Tokyo metropolitan area, Adachi et al. used a UCM coupled RCM to analyze the impact of urban scenarios developed by Yamagata et al. under the current climate and showed that compact city scenario (population is assumed to converge to central Tokyo) can mitigate the metropolitan area mean nighttime temperature by $0.1^{\circ} \mathrm{C}[15,16]$. Kusaka et al. also analyzed the Yamagata scenarios under the future climate condition and reported that similar results to those of Adachi et al. were obtained [17].

All of the above noted studies focused on the impact of urban form on air surface temperature. For more comprehensive assessment of heat-related health risks, however, inclusion of humidity and solar radiation is critical. WBGT is a widely used thermal index incorporating temperature, humidity, solar radiation, and wind speed [18]. A handful of studies have evaluated future changes of WBGT using UCM coupled RCMs [9, 19, 20], but none of these studies considered future urban changes.

The present study aims to provide a quantitative assessment of the impact of metropolitan-scale urban planning on the summer-time moist thermal environment under global warming. The study area is the Greater Tokyo Area, the world's largest metropolitan area with population of 38 million [5]. Dynamical downscaling simulations are conducted for current and future climate. For the latter, we consider future urban planning scenarios: the status quo scenario and two alternative scenarios (compact and dispersed city scenarios). A special attention will be given to the comparison of the global warming impact against the alternative urban planning impacts on the summer-time moist thermal environment. To this end, we use WBGT as a comprehensive thermal index, to incorporate temperature and humidity. To the best knowledge of the authors, the present study is the first assessment of the impact of future metropolitan-scale urban planning scenarios on moist thermal environment using dynamical downscaling approach.

\section{Data and Methods}

2.1. RCM Simulations. The Weather and Research Forecasting (WRF) model version 3.1.1 was used for regional climate simulations [21]. The model domain is setup as one-way nesting of three domains. The outermost domain (D01) covers the whole Japan with $27 \mathrm{~km}$ horizontal grid spacing. The middle domain (D02) is nested within D01 with $9 \mathrm{~km}$ horizontal grid spacing, and the innermost domain (D03) covering the Tokyo metropolitan area is nested within D02 with $3 \mathrm{~km}$ horizontal grid spacing (Figure 1(a)). The subsequent analysis will be based on the results from D03. The physics schemes, selected mainly based on Kusaka et al. [9], are as follows: the RRTMg radiation scheme [22], the WSM6 cloud microphysics scheme [23], and the YSU planetary boundary layer scheme [24]. The Kain-Fritch cumulus parameterization scheme [25] is activated for D01 and D02. For the surface, we use the Noah land surface model [26] coupled with the single-layer urban canopy model (UCM) developed by Kusaka et al. [27]. The UCM used in this study is a modified version of the one by Adachi et al. to incorporate the gridded urban fraction map, as well as gridded maps for sensible, latent, and anthropogenic heat fluxes [15]. Anthropogenic heat release is allowed to vary diurnally, roughly following the observations by Kikegawa et al. [28].

Due to the extensive computational cost required for DDS, simulations are targeted to August, as the heat-related health risk is maximized during this month. Simulations are conducted for July $2700 \mathrm{Z}$ to August $31 \mathrm{18Z}$ of each year of current and future climate simulation target years. The current and future climate simulations are conducted using the pseudo-global-warming (PGW) approach $[9,29]$. Initial and boundary forcing for current climate (August of 20002009) simulation is provided by the NCEP-FNL (National 
TABLE 1: Summary of dynamical downscaling experiments.

\begin{tabular}{lclr}
\hline & \multicolumn{1}{c}{ Period } & Initial/boundary conditions & Urban scenario \\
\hline Current & $2000-2009$ & NCEP-FNL reanalysis & Status quo \\
\hline \multirow{2}{*}{ Future } & $2070-2079($ SRES A1B) & Pseudo-global-warming data based on & Status quo \\
& & MRI-CGCM2.3.2 & Compact city \\
& & Dispersed city \\
\hline
\end{tabular}

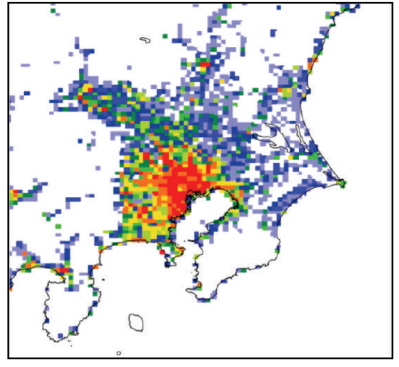

(a) UF (status quo)

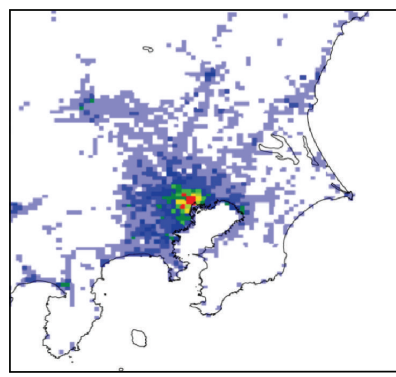

(d) $\mathrm{AH}$ (status quo)
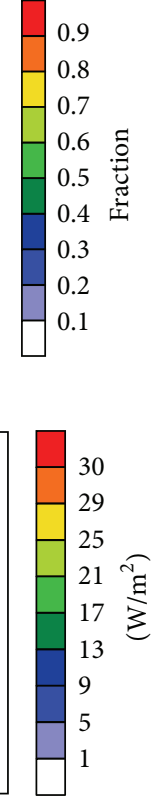

30
29
25
21
17
13
9
5
1

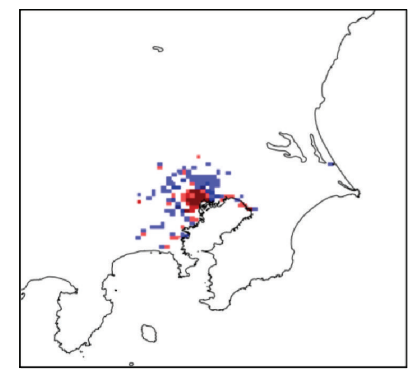

(e) $\Delta \mathrm{AH}$ (compact)
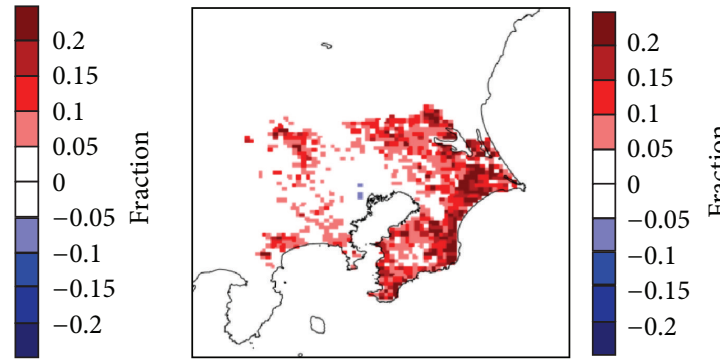

(c) $\triangle \mathrm{UF}$ (dispersed)
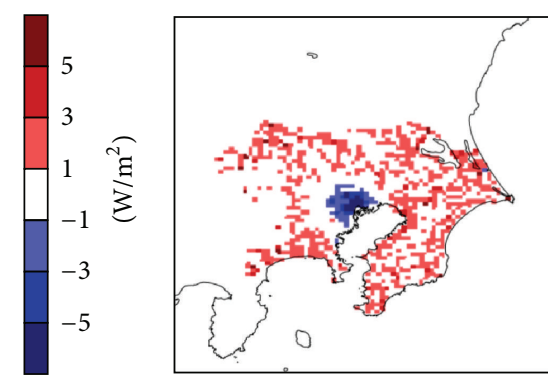

(f) $\triangle \mathrm{AH}$ (dispersed)

FIGURE 2: Spatial distributions of urban parameters: (a) urban fraction (UF) and (d) anthropogenic heat release (AH) for the status quo scenario. Differences of UF and AH relative to the status quo scenario are shown in (b) and (e), respectively, for the compact city scenario and in (c) and (f), respectively, for the dispersed city scenario (adapted and modified from [15]).

Center for Environmental Prediction Final Analysis) data. For future simulations, targeted for the 2070s under the A1B scenario in the IPCC 3rd Assessment Report, initial and boundary forcing is constructed by combining the NCEPFNL data and the mean future changes projected by MRICGCM2.3.2 (Table 1). Greenhouse gas concentration in the radiation scheme is modified to the values specified in the A1B scenario.

2.2. Urban Planning Scenarios. For the future climate simulations, we consider three types of metropolitan-scale urban scenarios as developed by Yamagata et al. [16]: (1) the status quo scenario, in which the future urban structure is assumed to be unchanged from today; (2) the compact city scenario, in which the population converges on central Tokyo to live in high-rise buildings; and (3) the dispersed city scenario, in which the population spreads out to the rural area surrounding Tokyo and depends on cars for commuting. These scenarios are reflected in the UCM by modifying the urban fraction and anthropogenic heat release as shown in Figure 2. Here, increases/decreases in the urban fraction are counterbalanced by decreases/increases in the green fraction. The focus here is to assess the impact of land surface modifications. Therefore, the total population in the greater Tokyo metropolitan area (and thus the total amount of anthropogenic heat release) is kept the same for the current and future scenarios, but its spatial variations are changed according to the urban scenarios. As briefly mentioned in Section 1, the impacts of the Yamagata urban scenarios on surface air temperature were previously analyzed in Adachi et al. [15]. Kusaka et al. also examined the impacts of the Yamagata scenarios in the future climate and compared them to the differences between two regional climate models [17].

2.3. Observational Data. The WBGT calculation requires air temperature, humidity, wind speed, and solar radiation; and the measurements for this full group of meteorological elements are only available at five sites in our analysis domain, as shown in Figure 1(b). Thus, hourly data were collected from these five stations and used as validation data for WBGT. In the case of air temperature observations, the automated meteorological data acquisition system (AMeDAS) provides measurements with much finer spatial distribution; hence AMeDAS data was used for air temperature validation. 
Observational data are collected for the current climate simulation period, August 2000-2009.

2.4. WBGT. WBGT is a widely used thermal index, especially in the regulation of the labor environment [30]. WBGT is based on the heat exchange between the human body surface and the surrounding air, via moist, radiative, and dry thermodynamics, with wet-bulb, globe, and dry-bulb temperatures representing each of these components, respectively. WBGT [ ${ }^{\circ} \mathrm{C}$ ] for an outdoor environment is formulated as follows:

$$
\mathrm{WBGT}=0.7 T_{w}+0.2 T_{g}+0.1 T_{a},
$$

where $T_{w}\left[{ }^{\circ} \mathrm{C}\right], T_{g}\left[{ }^{\circ} \mathrm{C}\right]$, and $T_{a}\left[{ }^{\circ} \mathrm{C}\right]$ are wet-bulb temperature, globe temperature (measured by a black globe thermometer), and air temperature, respectively. Here, $T_{w}$ is a function of air temperature, humidity, and air pressure. In this study, $T_{w}$ is obtained using a bilinear search algorithm incorporating Teten's formula (see (2)) and Sprung's formula (see (3)):

$$
\begin{aligned}
e_{\text {sat }}(T) & =6.1078 \times 10^{7.5 T /(237.3+T)}, \\
e(T) & =e_{\text {sat }}\left(T_{w}\right)-0.000622 P\left(T_{a}-T\right) .
\end{aligned}
$$

Here $e_{\text {sat }}(T)$ is saturation vapor pressure $[\mathrm{hPa}]$ at air temperature $T\left[{ }^{\circ} \mathrm{C}\right], e$ is vapor pressure $[\mathrm{hPa}]$, and $P$ is atmospheric pressure $[\mathrm{hPa}] . T_{g}$ depends on air temperature, solar radiation, and wind speed. In this study, $T_{g}$ is calculated using the empirical formula developed by Tonouchi and Murayama [31]:

$$
\begin{array}{ll}
T_{g}=T_{a}+12.1+0.0067 S-2.4 \sqrt{u} & (S>400), \\
T_{g}=T_{a}-0.3+0.0256 S-0.18 \sqrt{u} & (S \leq 400),
\end{array}
$$

where $S$ is solar radiation $\left[\mathrm{W} / \mathrm{m}^{2}\right]$ and $u$ is wind speed $[\mathrm{m} / \mathrm{s}]$.

\section{Results}

The subsequent analysis focuses on daytime (6:00-18:00 local time) given that heat stress is maximized during this time period. Climatological averages of daytime temperature and WBGT are calculated by taking hourly values during daytime hours and averaging over 10 months (i.e., August of 20002009).

3.1. Current Climate Reproducibility. As noted above, observational data for the full group of meteorological elements required for WBGT calculation are only available at five locations in our analysis domain. A previous study showed that spatial variations of climatological WBGT tend to be closely associated with air temperature variations [20]. Therefore, we first validate the simulated spatial variation of air temperature against the observed values from AMeDAS data; Figure 3 shows a comparison of the simulated and observed spatial variations of daytime mean air temperature for the current climate. The WRF model successfully captures the observed spatial variation of temperature. The highest temperature is found in central Tokyo, and this shows a clear representation of the urban heat island effect. In addition, the spatial correlation between the simulated and observed temperature is high, at 0.97. However, WRF has a low-temperature bias, with -0.5 as the analysis domain average.

Next, we examine the reproducibility of WBGT, using the meteorological observation station data (Figure 4). The simulated daytime mean WBGT generally agrees with the observed value, and the biases are relatively small, with -0.54 for Choshi, +0.22 for Maebachi, -0.07 for Tsukuba, and -0.22 for Utsunomiya. The bias for Tokyo is relatively high, at +0.68 ; however, on the whole these biases are well within the range of standard deviation.

3.2. Future Change in the Status Quo Urban Scenario. Differences between the future status quo simulation and the current climate simulation give the impact of global warming for the 2070s. Figure 5(a) shows the simulated future changes in August daytime average WBGT in the status quo urban scenario. A minimum of $2^{\circ} \mathrm{C}$ increase in WBGT is projected for the entire analysis domain, with a greater increase found in mountain areas and in the plain area northwest of central Tokyo. The projected future changes at the five meteorological observation stations are also shown in Figure 4, with projected increases ranging from +2.05 to +2.09 . All these increases are statistically significant, at the 99\% level according to the two-sided Student's $t$-test.

The simulated future changes in each of the WBGT's components are shown in Figures 5(b)-5(d). In general, $T_{g}$ shows the highest increase for the whole analysis domain, followed by $T_{a}$ and $T_{w}$. The largest contribution for the increase in WBGT comes from $T_{w}$, however, because of its coefficient of 0.7 in the WBGT formula (see (1)). The profound increases of WBGT in the mountain region appear to be associated with the $T_{w}$ increase (Figures 5(a) and $5(\mathrm{~b})$ ), whereas the greater WBGT increases in the plain area northwest of central Tokyo appear to be associated with the increases in $T_{g}$ and $T_{a}$ (Figures 5(a), 5(c), and 5(d)).

\subsection{Impacts of the Future Alternative Urban Scenarios on} WBGT. The impacts of the future alternative urban scenarios (dispersed and compact city scenarios) are evaluated. Figures 6(a) and 6(b) show the differences of August daytime mean WBGT in each of the alternative urban scenarios from the status quo scenario in future climate simulations. The impacts of the alternative urban scenarios range from -0.4 to $+0.4^{\circ} \mathrm{C}$. In comparison with the $2^{\circ} \mathrm{C}$ warming of WBGT due to global warming, the impact of the alternative urban scenarios is fairly limited. However, some specific impacts are statistically significant (Figures 6(c) and 6(d)).

In the compact city scenario, the WBGT difference from the status quo scenario shows a very sporadic nature. There is a general reduction in the vicinity of central Tokyo and increases on the outskirts of the metropolitan area. Areas of statistically significant anomalies are found in southern Chiba (hereafter SC, denoted by a black circle in Figures 6(c) and 6(d)) and along the mountains west of Tokyo. These sporadic natures of the WBGT differences and the statistical 


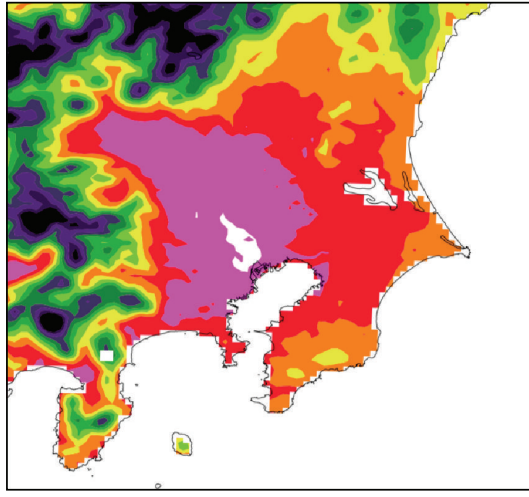

(a) WRF simulation
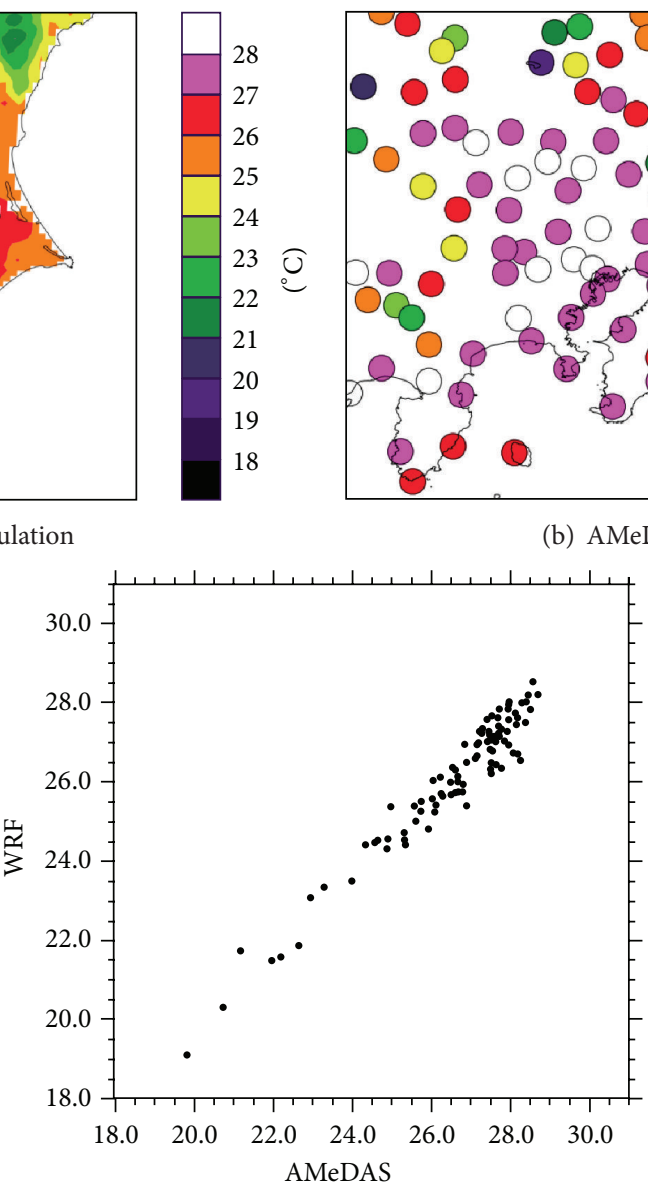

(c) Scatter diagram

FIgURE 3: Spatial distributions of August daytime mean air temperature for the current climate (2000-2009) from (a) WRF simulation and (b) AMeDAS observations. A scatter diagram for the simulated and the observed air temperatures is shown in (c).

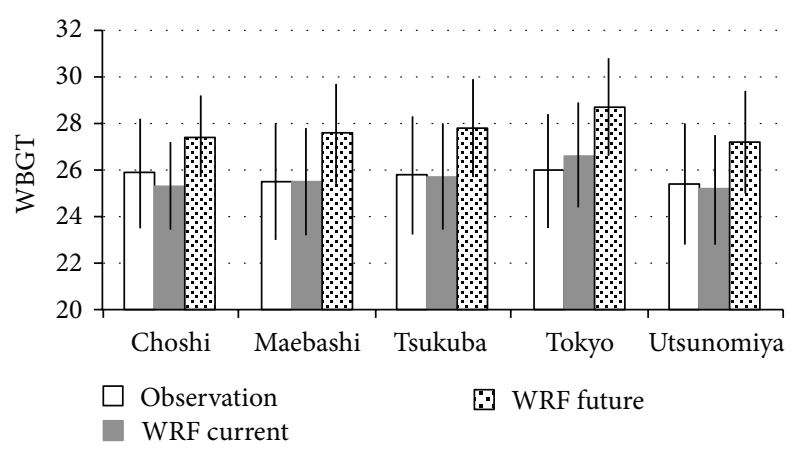

FIGURE 4: August daytime mean WBGT from the station observations (white bars), the current climate simulation (gray bars), and the future climate simulation with the status quo urban scenario (dotted bars). Error bars indicate standard deviation.

significance imply that the response of the climatological mean WBGT to changes in the metropolitan urban structure may be nonlinear.

In the dispersed city scenario, the WBGT anomaly roughly follows that of temperature impact, with a general increase in the rural area and a weak reduction in central Tokyo. However, these changes are not statistically significant. Instead, statistically significant reductions are found in SC and in the mountainous area west of Tokyo, and these reductions are contrary to what would be expected from temperature impact. Section 4 offers a detailed discussion of possible reasons for the foregoing alternative urban scenario impacts on WBGT.

3.4. Decomposition of WBGT Responses to Future Alternative Urban Scenarios. The impacts of the alternative urban scenarios on each of the WBGT components are shown in Figure 7. Differences in $T_{a}$ for the compact scenario show an increase in the central Tokyo surrounded by a reduction area, whereas for the dispersed scenario a concentrated reduction is found in the central Tokyo surrounded by a wide area of increased $T_{a}$ (Figures $7(\mathrm{e}$ ) and $7(\mathrm{f})$ ). These responses of air temperature to the alternative urban scenarios are in accordance with the previous studies [15, 17]. We further note that the areas of apparent $T_{a}$ responses are confined to the area of land surface modifications for the alternative urban scenarios (Figure 2). In this area, $T_{g}$ shows similar responses 


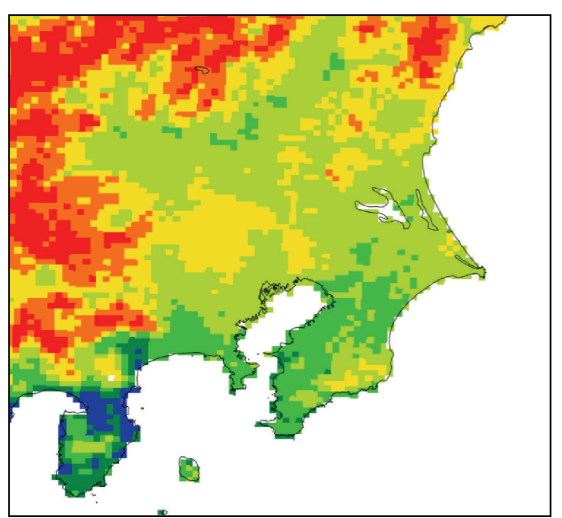

(a) WBGT

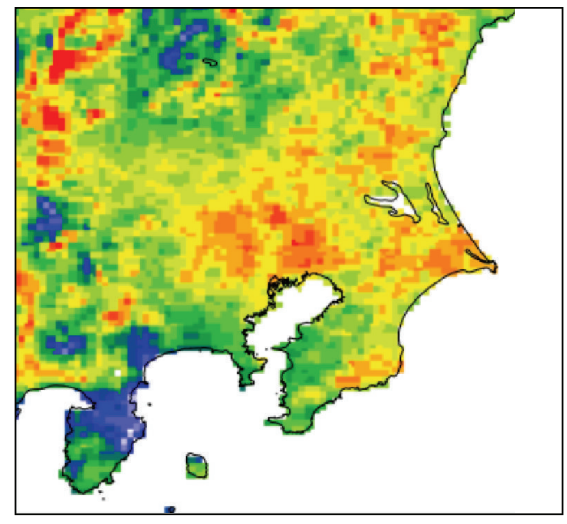

(c) $T_{g}$ (globe temp.)

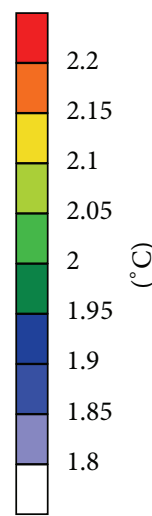

2.2

.05

95

9

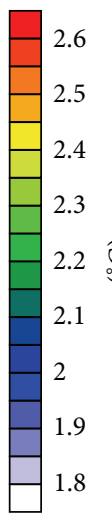

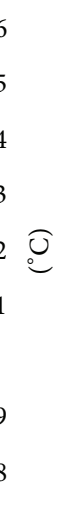

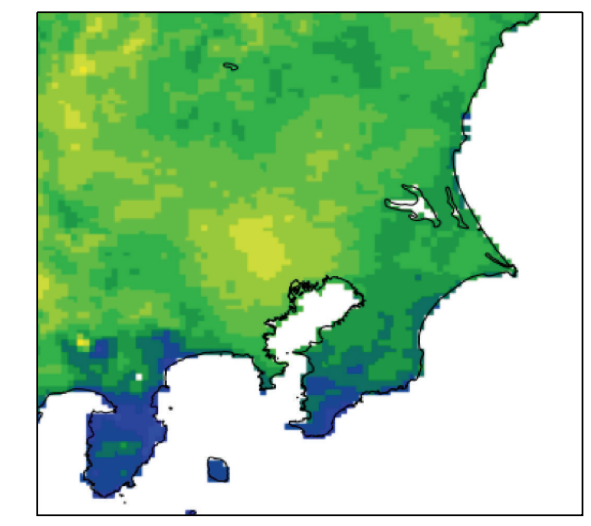

(d) $T_{a}$ (air temp.)

(b) $T_{w}$ (wet-bulb temp.)
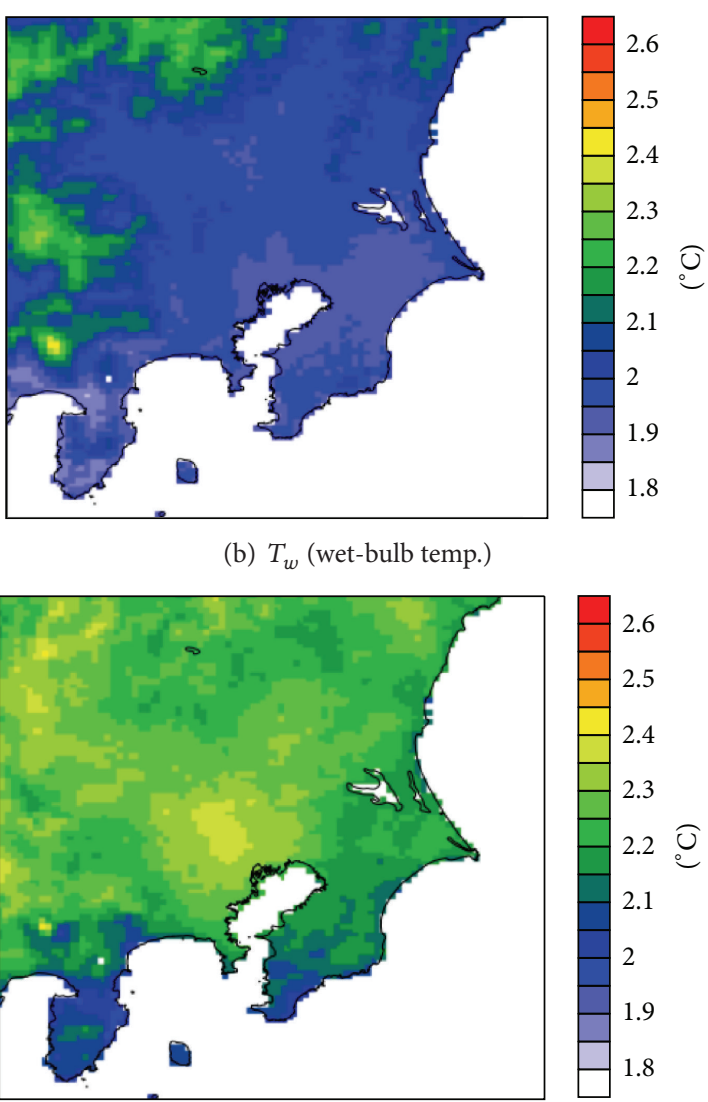

\section{.}

FIGURE 5: Spatial distributions of the simulated future change for the 2070s with the status quo urban scenario: (a) WBGT, (b) wet-bulb, (c) globe, and (d) air temperature. All variables are August daytime averages.

to those of $T_{a}$. However, $T_{g}$ responses also appear outside of the land surface modification with sporadic nature (Figures $7(\mathrm{c})$ and $7(\mathrm{~d}))$. This is considered to be associated with the remote influence via nonlinear processes of cloud formation. The $T_{w}$ responses show a binary-like nature, in that responses are either within a range of -0.05 to $+0.05^{\circ} \mathrm{C}$, or greater than $\pm 0.4^{\circ} \mathrm{C}$ (Figures $7(\mathrm{a})$ and $7(\mathrm{~b})$ ). Areas of responses greater than $\pm 0.4^{\circ} \mathrm{C}$ roughly correspond to the statistically significant WBGT changes (Figures 6(c) and 6(d)). As discussed in Section 3.2, $T_{w}$ has the largest coefficient in the WBGT formulation. Given that alternative urban scenario responses of all WBGT components range from -0.5 to $+0.5^{\circ} \mathrm{C}, T_{w}$ has the greatest control in determining the sign of change in WBGT.

\section{Discussions}

4.1. Impacts of Urban Land Surface Modifications on $T_{w}$. The above results indicate that changes in August daytime mean WBGT are largely controlled by $T_{w}$ changes, both for global warming and for the alternative future urban scenario impacts. The following discussion considers the behavior of $T_{w}$ in the context of the urban land surface modification. Here we use the model grid points in SC area denoted by black circles in Figures 6(c) and 6(d), as they exhibit opposite
TABLE 2: Impacts of the future alternative urban scenarios (dispersed and compact city scenarios) on wet-bulb temperature $\left(T_{w}\right)$, air temperature $\left(T_{a}\right)$, and vapor pressure $(\mathrm{Vp})$, each averaged over the model grid points with statistically significant responses in southern Chiba (area denoted by black circles in Figures 6(c) and 6(d)).

\begin{tabular}{lccc}
\hline & $\Delta T_{w}\left[{ }^{\circ} \mathrm{C}\right]$ & $\Delta T_{a}\left[{ }^{\circ} \mathrm{C}\right]$ & $\Delta \mathrm{Vp}[\mathrm{hPa}]$ \\
\hline Dispersed & -0.52 & 0.16 & -1.44 \\
Compact & 0.39 & -0.01 & 1.02 \\
\hline
\end{tabular}

WBGT changes by urban scenarios and show relatively more coherent nature in space (i.e., model grid points with statistically significant changes are clustered in this area). The SC area-averaged responses of $T_{w}, T_{a}$ and humidity (here vapor pressure, denoted as $\mathrm{Vp}$, is used in order to eliminate any influence of $T_{a}$ ) are shown in Table 2. $T_{w}$ increases if $T_{a}$ and Vp increase ((2) and (3)). In SC, for the compact city scenario, $T_{a}$ has little response $\left(-0.01^{\circ} \mathrm{C}\right)$ but $\mathrm{Vp}$ is increased $(+1.02 \mathrm{hPa})$. The resulting response of $T_{w}$ is thus an increase $\left(+0.39^{\circ} \mathrm{C}\right)$. On the other hand, for the dispersed scenario, $T_{a}$ is increased $\left(+0.16^{\circ} \mathrm{C}\right)$ but $\mathrm{Vp}$ is decreased $(-1.44 \mathrm{hPa})$; the resulting $T_{w}$ response is negative $\left(-0.52^{\circ} \mathrm{C}\right)$. Here, the decrease in $T_{w}$ in the dispersed city scenario appears to be the result of the reduction in $\mathrm{Vp}$ outweighing the increase 


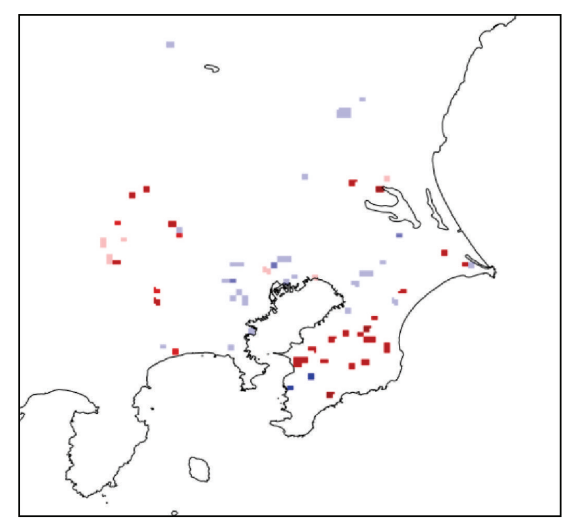

(a) $\triangle \mathrm{WBGT}$ (compact)

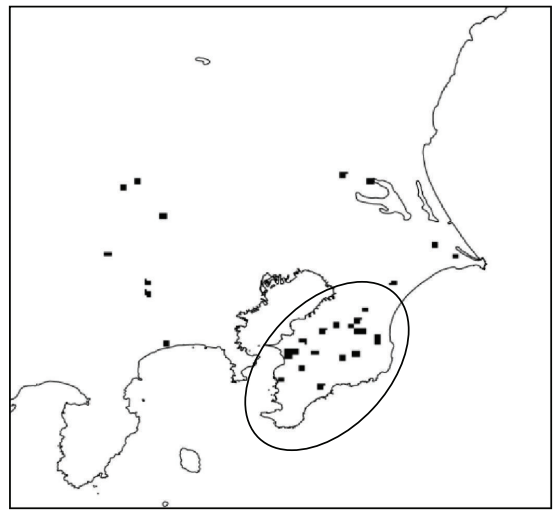

(c) Significance (compact)

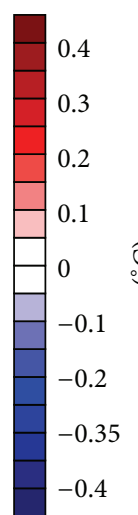

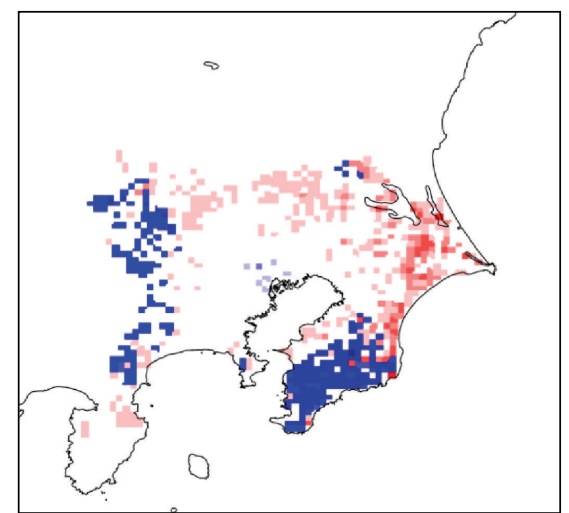

(b) $\triangle \mathrm{WBGT}$ (dispersed)

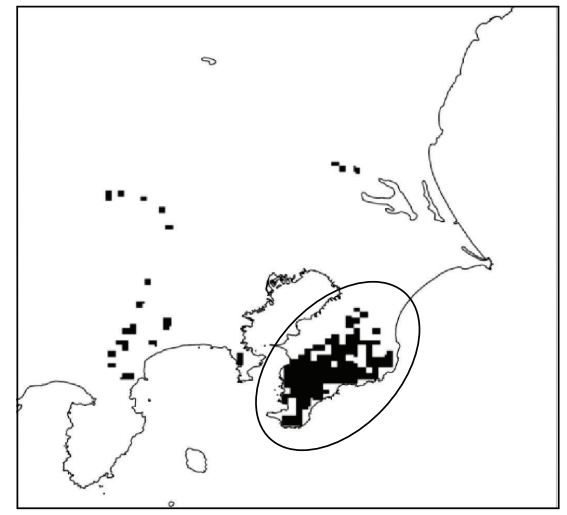

(d) Significance (dispersed)

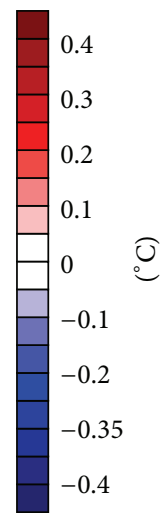

. 


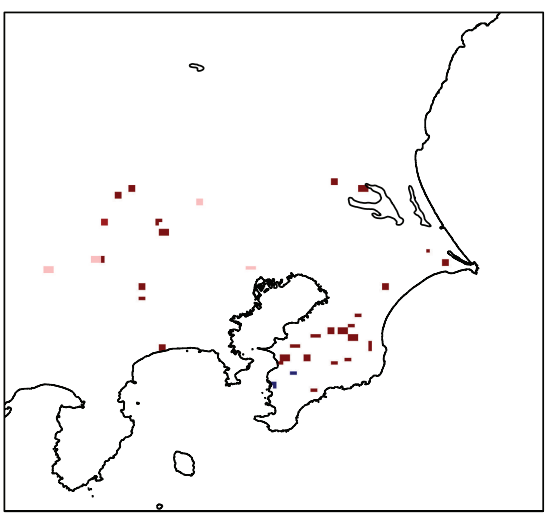

(a) $\Delta T_{w}$ (compact)

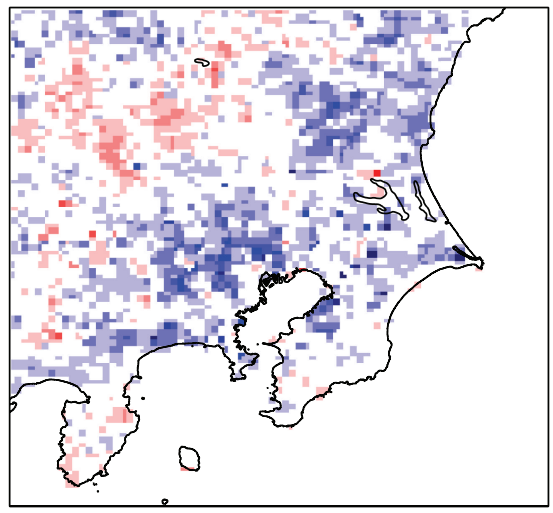

(c) $\Delta T_{g}$ (compact)

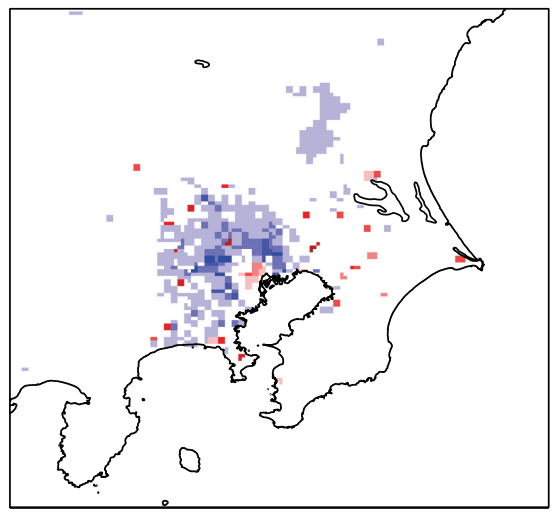

(e) $\Delta T_{a}$ (compact)
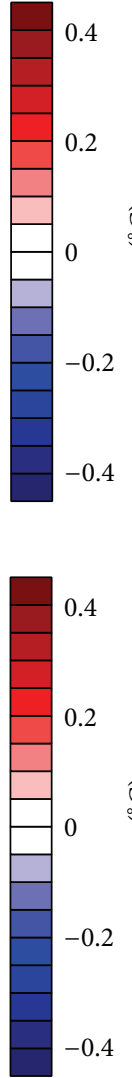

0.4

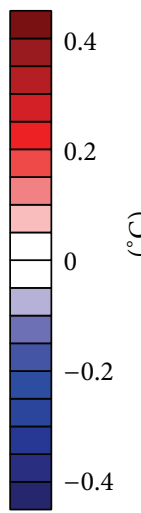

0.4
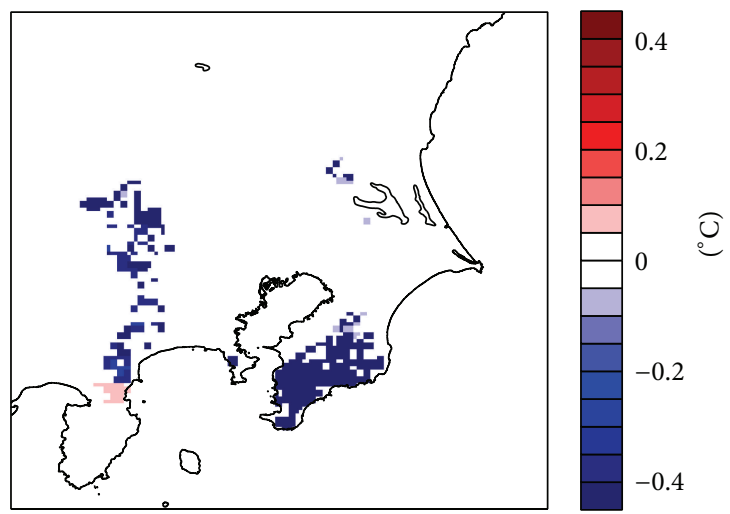

(b) $\Delta T_{w}$ (dispersed)
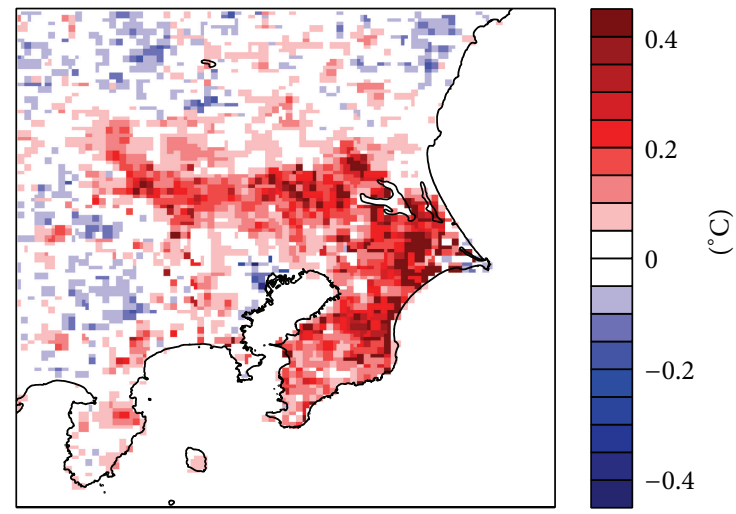

(d) $\Delta T_{g}$ (dispersed)
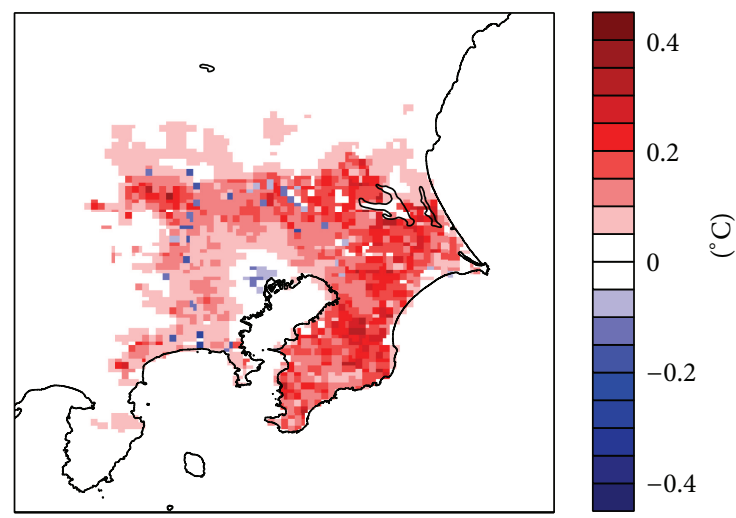

(f) $\Delta T_{a}$ (dispersed)

FIGURE 7: Responses of WBGT's components (top: wet-bulb temperature, middle: globe temperature, and bottom: air temperature) to the compact (left) and the dispersed (right) city urban scenarios. All responses are August daytime averages and are relative to the status quo scenario in the future climate.

to the current mature state of Tokyo, where there is little room left for substantial changes in urban land surface. In addition, Tokyo metropolitan area is surrounded by ocean and mountains thus further expansion of urbanized area is unlikely. Some of the studies that reported significant thermal environment changes by urbanization assumed horizontal expansion of urbanized areas whereby replacing existing natural land surface to urbanized one [10,12]. Such expansion is not considered in this study.
4.3. Future Tasks. In the present study, we have focused on the impacts of urban land surface modifications to the moist thermal environment. However, there are many factors that may substantially alter the moist thermal environment in urbanized areas. For example, aerosols are known to modulate moist processes (such as fog, cloud, and precipitation formations) within and outside of urbanized areas [36]; therefore they can potentially impact WBGT via changing the amount of insolation reaching the ground surface. We also 


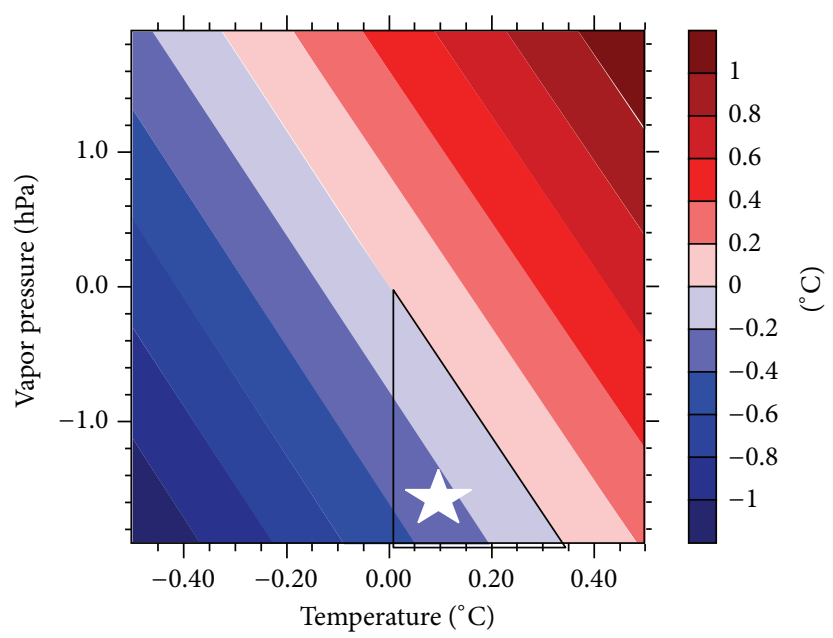

Figure 8: $T_{w}$ anomalies as a function of temperature $\left(T_{a}\right)$ and vapor pressure (Vp). Anomalies are based on the climatological value of $T_{w}$ in southern Chiba in the status quo scenario. Tw anomalies denoted by black triangle show $T_{w}$ reductions due to Vp reductions overpowering $T_{a}$ increases. White star indicates $T_{w}$ response to simulated change in temperature and vapor pressure in the dispersed scenario for southern Chiba.

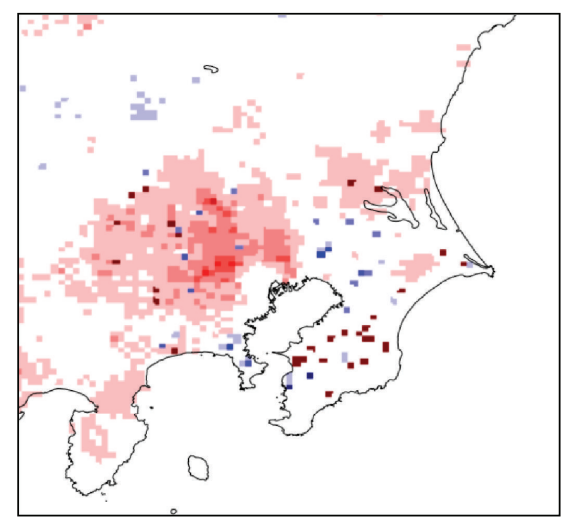

(a) $\Delta \mathrm{Vp}$ (compact)

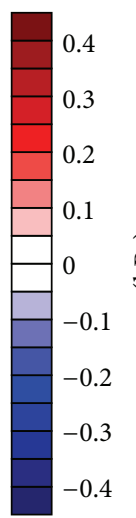

(20)
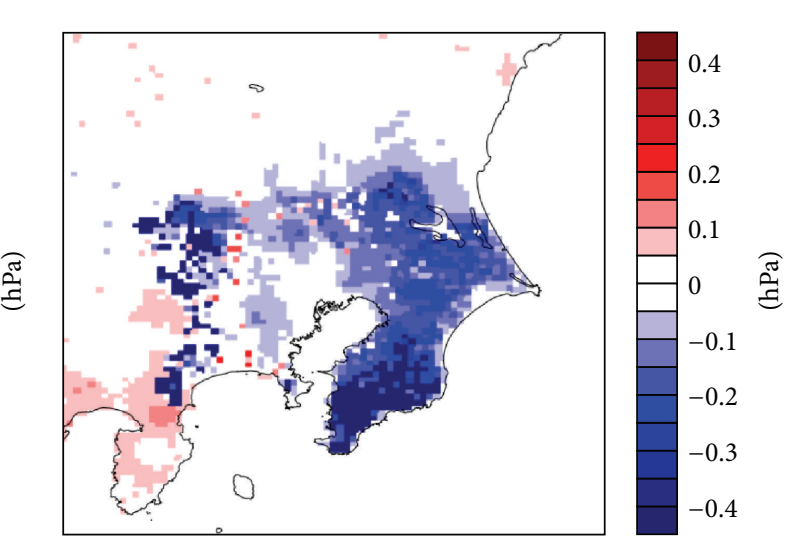

(b) $\Delta \mathrm{Vp}$ (dispersed)

FIGURE 9: Responses of vapor pressure to the (a) compact and (b) dispersed scenarios. Responses are August daytime averages and are relative to the status quo scenario in the future climate.

note that, at street level, solar insolation is largely affected by the complex surface structure of urbanized area, as has been demonstrated by previous studies [37, 38]. Explicit treatments of individual buildings and roadside trees are required for detailed assessment of radiation at street level but are not considered in the present study due to the limited computational capacity. Other key factors not considered here include the day-to-day variation of anthropogenic heat release associated with variable weather condition and the anticipated reduction of the Japanese population. Assessments of these factors are left for future studies.

\section{Conclusions}

Taking the Tokyo metropolitan area as an example, the present study assessed the impact of metropolitan-scale urban planning scenarios on a moist thermal environment in the context of climate change. Special attention was given to the relative influence of temperature and humidity. In this regard, WBGT was used as an index for evaluating comprehensive heat stress, taking both temperature and humidity into consideration. Dynamical downscaling simulations were conducted based on three metropolitan-scale urban scenarios for Tokyo, developed by Yamagata et al. [15]: status quo (future urban structure remains unchanged), dispersed city (population spreads out to rural area), and compact city (population converges on central Tokyo).

The future projection for the status quo scenario shows a $2-2.4^{\circ} \mathrm{C}$ increase in daytime mean WBGT. The overall impact of the two alternative urban scenarios was estimated to be from -0.4 to $+0.4^{\circ} \mathrm{C}$, which is relatively small compared to the global warming signal. These findings indicate that metropolitan-scale urban planning may not be effective for heat mitigation, at least for Tokyo. The limited effectiveness of 


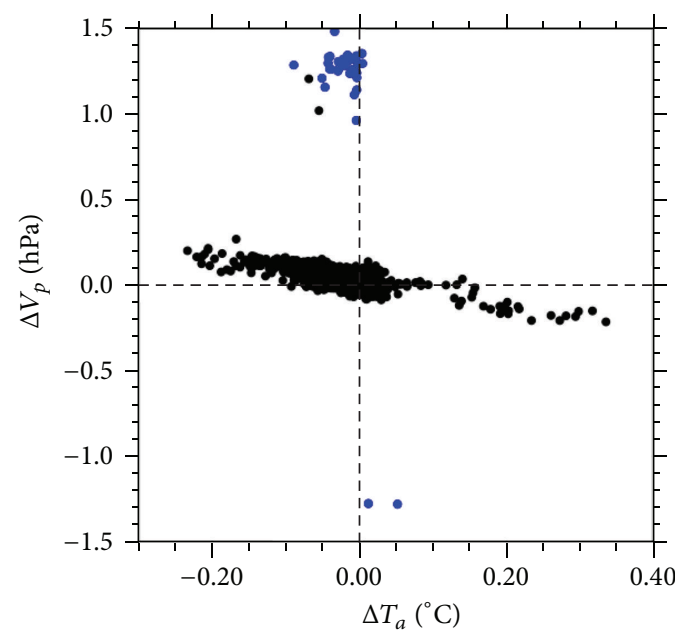

(a) Compact

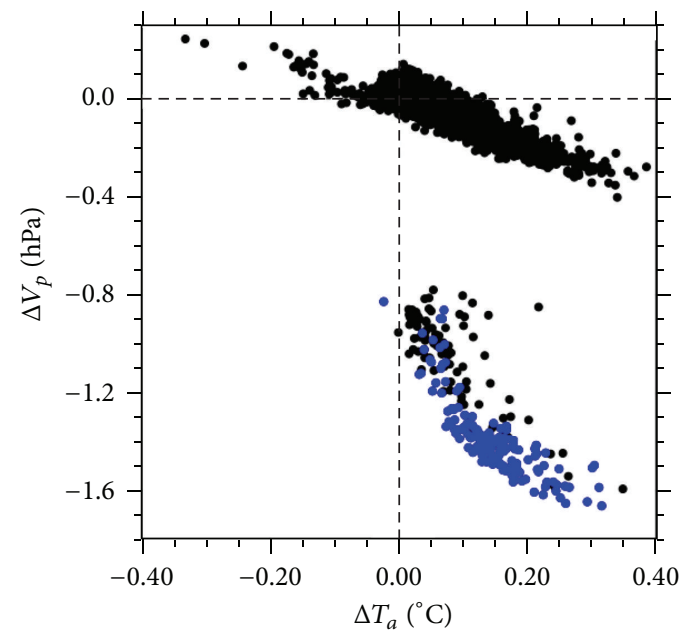

(b) Dispersed

Figure 10: Scatter diagrams of August mean daytime average vapor pressure (Vp) and air temperature $\left(T_{a}\right)$ responses to alternative urban scenarios; (a) compact and (b) dispersed. Responses are relative to the status quo urban scenario in the future climate. Blue dots are values from model grid points with statistically significant WBGT responses shown in Figures 6(c) and 6(d).

urban planning scenarios is considered in part to the mature state of Tokyo's urban structure, where there is little room left for substantial modifications of urban land surface.

While small in magnitude, some the specific urban scenario impacts were statistically significant. Statistically significant changes were sporadic in nature, indicating that the response of the climatological mean WBGT to changes in urban structure may be highly nonlinear. Some of the alternative urban scenario impacts on WBGT were revealed to be opposite to temperature response, despite the fact that WBGT is strongly dependent on temperature. In particular, southern Chiba showed a statistically significant reduction in WBGT in the dispersed city scenario, in spite of the temperature increase; and the respective area analysis showed that this reduction was induced by the greater impact of the humidity reduction outweighing the temperature increase. No necessary correlation was observed between the reduction in humidity and changes in the urban and green fractions, suggesting that nonlocal changes may have a causal role in this reduction.

\section{Conflict of Interests}

The authors declare that there is no conflict of interests regarding the publication of this paper.

\section{Acknowledgments}

This study was conducted under the SOUSEI Program of the Ministry of Education, Culture, Sports, Science and Technology (MEXT) of Japan. Parts of the study were also funded by the Global Environment Research Fund (S-5) of the Ministry of the Environment, Japan, and by the Research Program on Climate Change Adaptation (RECCA) of MEXT. Special thanks are due to Dr. Sachiho A. Adachi for providing the version of WRF used in this study along with the urban scenario land use database. WRF simulations were performed on the super computer T2K at the Center for Computational Sciences at the University of Tsukuba, under the Interdisciplinary Computational Sciences Program.

\section{References}

[1] E. Kalnay and M. Cai, "Impact of urbanization and land-use change on climate," Nature, vol. 423, no. 6939, pp. 528-531, 2003.

[2] L. Zhou, R. E. Dickinson, Y. Tian et al., "Evidence for a significant urbanization effect on climate in China," Proceedings of the National Academy of Sciences of the United States of America, vol. 101, no. 26, pp. 9540-9544, 2004.

[3] F. Fujibe, "Detection of urban warming in recent temperature trends in Japan," International Journal of Climatology, vol. 29, no. 12, pp. 1811-1822, 2009.

[4] Japan Meteorological Agency, Heatisland Monitoring Report, 2014, http://www.data.jma.go.jp/cpdinfo/himr/2014/himr2014 .pdf.

[5] United Nations, World Urbanization Prospects: The 2014 Revision, 2014, http://esa.un.org/unpd/wup/Highlights/WUP2014Highlights.pdf.

[6] IPCC, Climate Change 2013: The Physical Science Basis, Contribution of Working Group I to the Fifth Assessment Report of the Intergovernmental Panel on Climate Change, edited by $\mathrm{T}$. F. Stocker, D. Qin, G.-K. Plattner et al., Cambridge University Press, Cambridge, UK, 2013.

[7] J. A. Patz, D. Campbell-Lendrum, T. Holloway, and J. A. Foley, "Impact of regional climate change on human health," Nature, vol. 438, no. 7066, pp. 310-317, 2005.

[8] H. Kusaka and F. Kimura, "Coupling a single-layer urban canopy model with a simple atmospheric model: impact on urban heat island simulation for an idealized case," Journal of the Meteorological Society of Japan, vol. 82, no. 1, pp. 67-80, 2004. 
[9] H. Kusaka, M. Hara, and Y. Takane, "Urban climate projection by the WRF model at 3-km horizontal grid increment: dynamical downscaling and predicting heat stress in the 2070's August for Tokyo, Osaka, and Nagoya metropolises," Journal of the Meteorological Society of Japan, vol. 90, pp. 47-63, 2012.

[10] M. Georgescu, M. Moustaoui, A. Mahalov, and J. Dudhia, "Summer-time climate impacts of projected megapolitan expansion in Arizona," Nature Climate Change, vol. 3, no. 1, pp. 37-41, 2013.

[11] S. A. Adachi, F. Kimura, H. Kusaka, T. Inoue, and H. Ueda, "Comparison of the impact of global climate changes and urbanization on summertime future climate in the Tokyo metropolitan area," Journal of Applied Meteorology and Climatology, vol. 51, pp. 1441-1454, 2012.

[12] D. Argüeso, J. P. Evans, L. Fita, and K. J. Bormann, “Temperature response to future urbanization and climate change," Climate Dynamics, vol. 42, no. 7-8, pp. 2183-2199, 2014.

[13] D. W. Shin and G. A. Baigorria, "Potential influence of land development patterns on regional climate: a summer case study in the Central Florida," Natural Hazards, vol. 62, no. 3, pp. 877$885,2012$.

[14] X. Ke, F. Wu, and C. Ma, "Scenario analysis on climate change impacts of urban land expansion under different urbanization patterns: a case study of Wuhan metropolitan," Advances in Meteorology, vol. 2013, Article ID 293636, 12 pages, 2013.

[15] S. A. Adachi, F. Kimura, H. Kusaka et al., "Moderation of summertime heat island phenomena via modification of the urban form in the Tokyo metropolitan area," Journal of Applied Meteorology and Climatology, vol. 53, no. 8, pp. 1886-1900, 2014.

[16] Y. Yamagata, H. Seya, and K. Nakamichi, "Scenario analysis of the future urban land use in the Tokyo metropolitan area," Journal of Society of Environmental Science, vol. 24, no. 3, pp. 169-179, 2011.

[17] H. Kusaka, S. A. Adachi, A. Suzuki-Parker, K. Fujita, M. Hara, and Y. Yamagata, "Urban climate projection in Tokyo for the 2050's August under the RCP4.5 scenario," in Proceedings of the 8th International Conference on Urban Climates, pp. 587-589, Dublin, Ireland, August 2012.

[18] C. P. Yagulou and C. D. Minard, "Control of heat casualities at military training centers," AMA Archives of Industrial Health, vol. 16, pp. 302-316, 1987.

[19] H. Altinsoy and H. A. Yildirim, "Labor productivity losses over western turkey in the twenty-first century as a result of alteration in WBGT,' International Journal of Biometeorology, vol. 59, no. 4, pp. 463-471, 2015.

[20] A. Suzuki-Parker and H. Kusaka, "Future projection of thermal environment in Japan using WBGT ", Japanese Journal of Biometeorology, vol. 52, pp. 59-72, 2015.

[21] W. C. Skamarock, J. B. Klemp, J. Dudhia et al., "A description of the advanced research WRF version 3," NCAR Technical Note NCAR/TN-475+STR, 2008.

[22] M. J. Iacono, J. S. Delamere, E. J. Mlawer, M. W. Shephard, S. A. Clough, and W. D. Collins, "Radiative forcing by long-lived greenhouse gases: calculations with the AER radiative transfer models," Journal of Geophysical Research D: Atmospheres, vol. 113, no. D13, Article ID D13103, 2008.

[23] S.-Y. Hong, J. Dudhia, and S.-H. Chen, "A revised approach to ice microphysical processes for the bulk parameterization of clouds and precipitation," Monthly Weather Review, vol. 132, no. 1, pp. 103-120, 2004.
[24] S.-Y. Hong, Y. Noh, and J. Dudhia, "A new vertical diffusion package with an explicit treatment of entrainment processes," Monthly Weather Review, vol. 134, no. 9, pp. 2318-2341, 2006.

[25] J. S. Kain, "The Kain-Fritsch convective parameterization: an update," Journal of Applied Meteorology, vol. 43, no. 1, pp. 170181, 2004.

[26] F. Chen and J. Dudhia, "Coupling an advanced land-surface/ hydrology model with the Penn State/NCAR MM5 modeling system. Part I: model description and implementation," Monthly Weather Review, vol. 129, no. 4, pp. 569-585, 2001.

[27] H. Kusaka, H. Kondo, Y. Kikegawa, and F. Kimura, "A simple single-layer urban canopy model for atmospheric models: comparison with multi-layer and slab models," Boundary-Layer Meteorology, vol. 101, no. 3, pp. 329-358, 2001.

[28] Y. Kikegawa, A. Tanaka, Y. Ohashi, T. Ihara, and Y. Shigeta, "Observed and simulated sensitivities of summertime urban surface air temperatures to anthropogenic heat in downtown areas of two Japanese Major Cities, Tokyo and Osaka," Theoretical and Applied Climatology, vol. 117, no. 1-2, pp. 175-193, 2014.

[29] F. Kimura and A. Kito, "Downscaling by pseudo global warming method," Final Report, ICCAP Research Institute for Humanity and Nature, Kyoto, Japan, 2007.

[30] K. Parsons, "Heat stress standard ISO 7243 and its global application," Industrial Health, vol. 44, no. 3, pp. 368-379, 2006.

[31] T. Tonouchi and S. Murayama, "Regional characteristics of heatstroke danger level and HWDI," Japanese Journal of Biometeorology, vol. 45, no. 3, p. S62, 2008.

[32] H. Kusaka, F. Kimura, H. Hirakuchi, and M. Mizutori, "The effects of land-use alteration on the sea breeze and daytime heat island in the Tokyo metropolitan area," Journal of the Meteorological Society of Japan, vol. 78, no. 4, pp. 405-420, 2000.

[33] A. Martilli, "A two-dimensional numerical study of the impact of a city on atmospheric circulation and pollutant dispersion in a coastal environment," Boundary-Layer Meteorology, vol. 108, no. 1, pp. 91-119, 2003.

[34] A. Lemonsu, R. Kounkou-Arnaud, J. Desplat, J.-L. Salagnac, and V. Masson, "Evolution of the Parisian urban climate under a global changing climate," Climatic Change, vol. 116, no. 3-4, pp. 679-692, 2013.

[35] H. Kusaka, K. Nawata, A. Suzuki-Parker, Y. Takane, and N. Furuhashi, "Mechanism of precipitation increase with urbanization in Tokyo as revealed by ensemble climate simulations," Journal of Applied Meteorology and Climatology, vol. 53, no. 4, pp. 824-839, 2014.

[36] V. Ramanathan and Y. Feng, "Air pollution, greenhouse gases and climate change: global and regional perspectives," Atmospheric Environment, vol. 43, no. 1, pp. 37-50, 2009.

[37] Á. Gulyás, J. Unger, and A. Matzarakis, "Assessment of the microclimatic and human comfort conditions in a complex urban environment: modelling and measurements," Building and Environment, vol. 41, no. 12, pp. 1713-1722, 2006.

[38] M. Nikolopoulou and S. Lykoudis, "Thermal comfort in outdoor urban spaces: analysis across different European countries," Building and Environment, vol. 41, no. 11, pp. 1455-1470, 2006. 

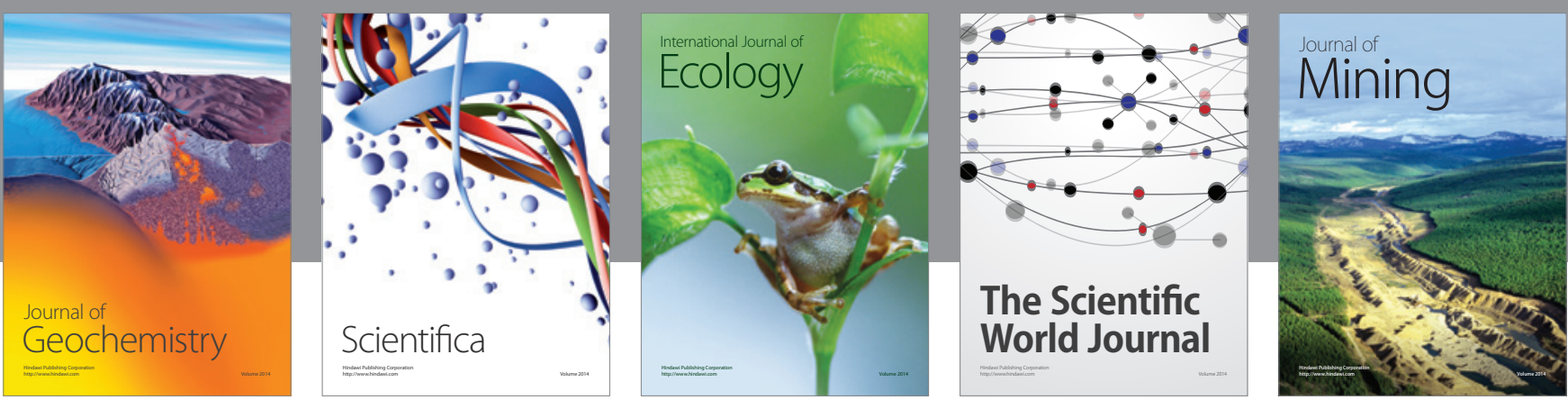

The Scientific World Journal
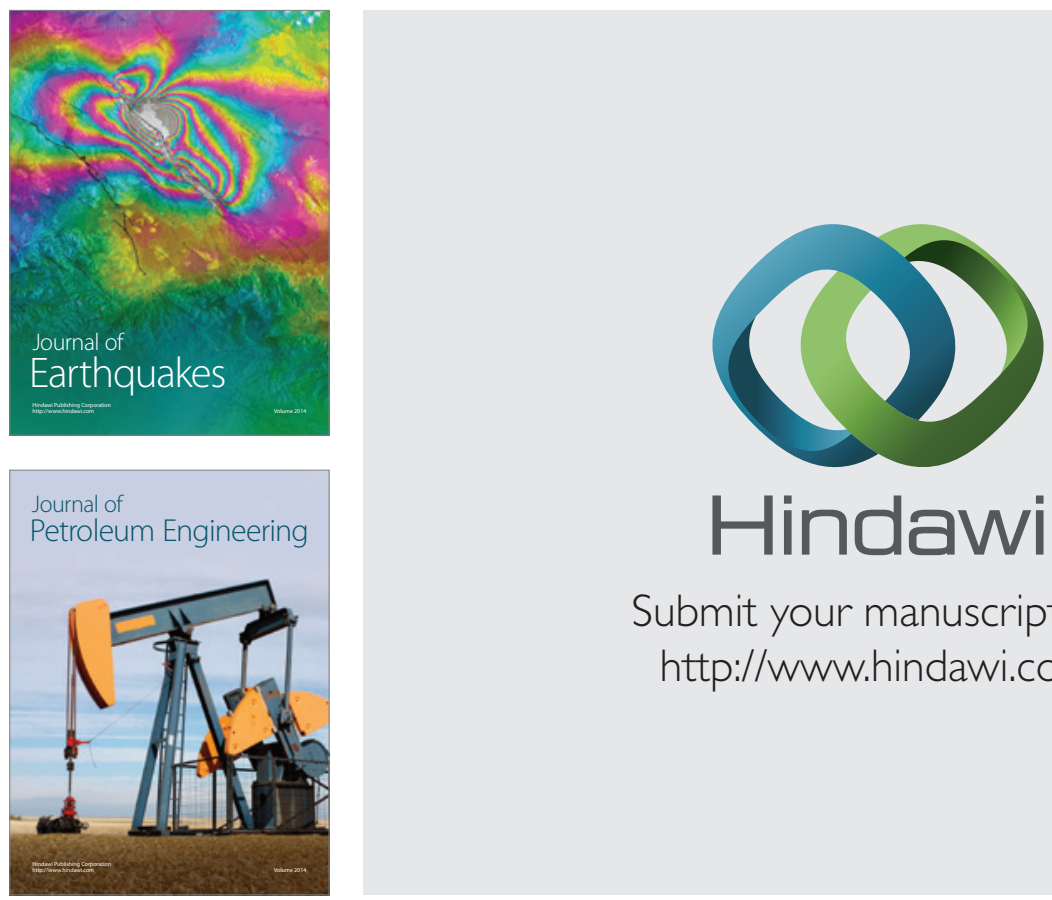

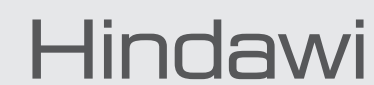

Submit your manuscripts at

http://www.hindawi.com
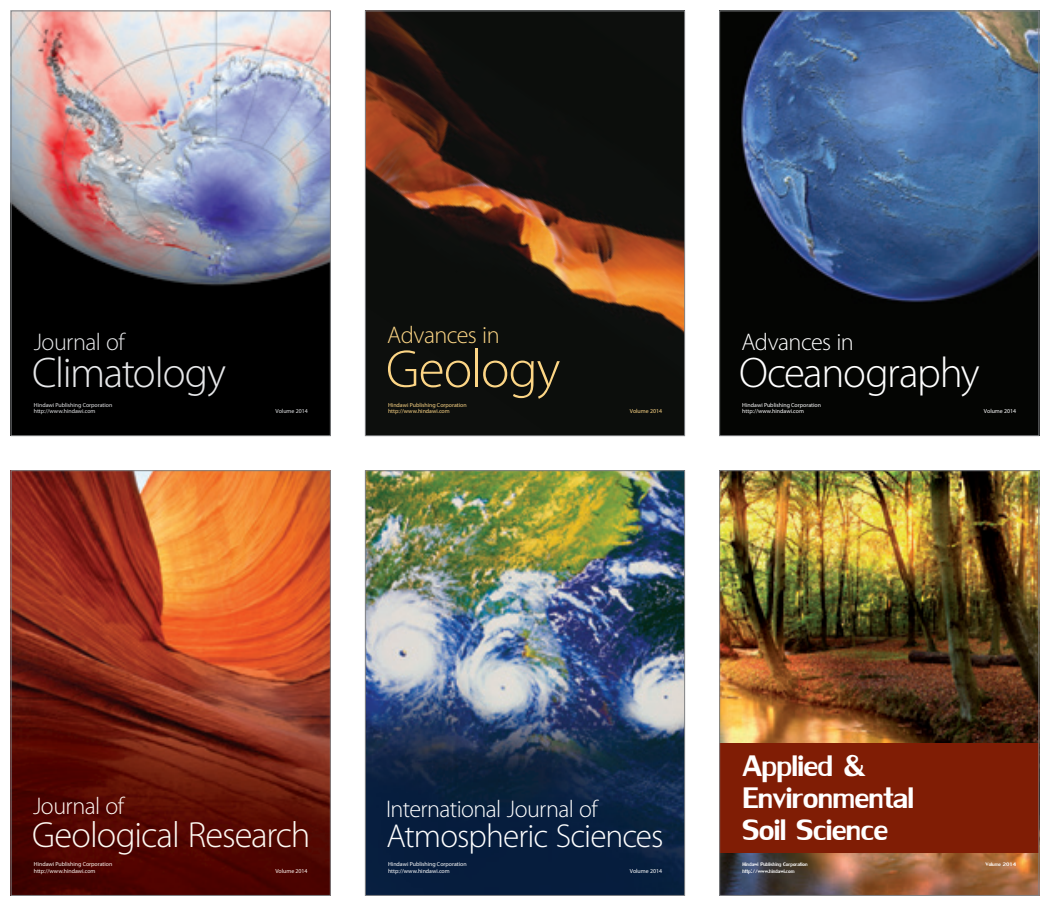
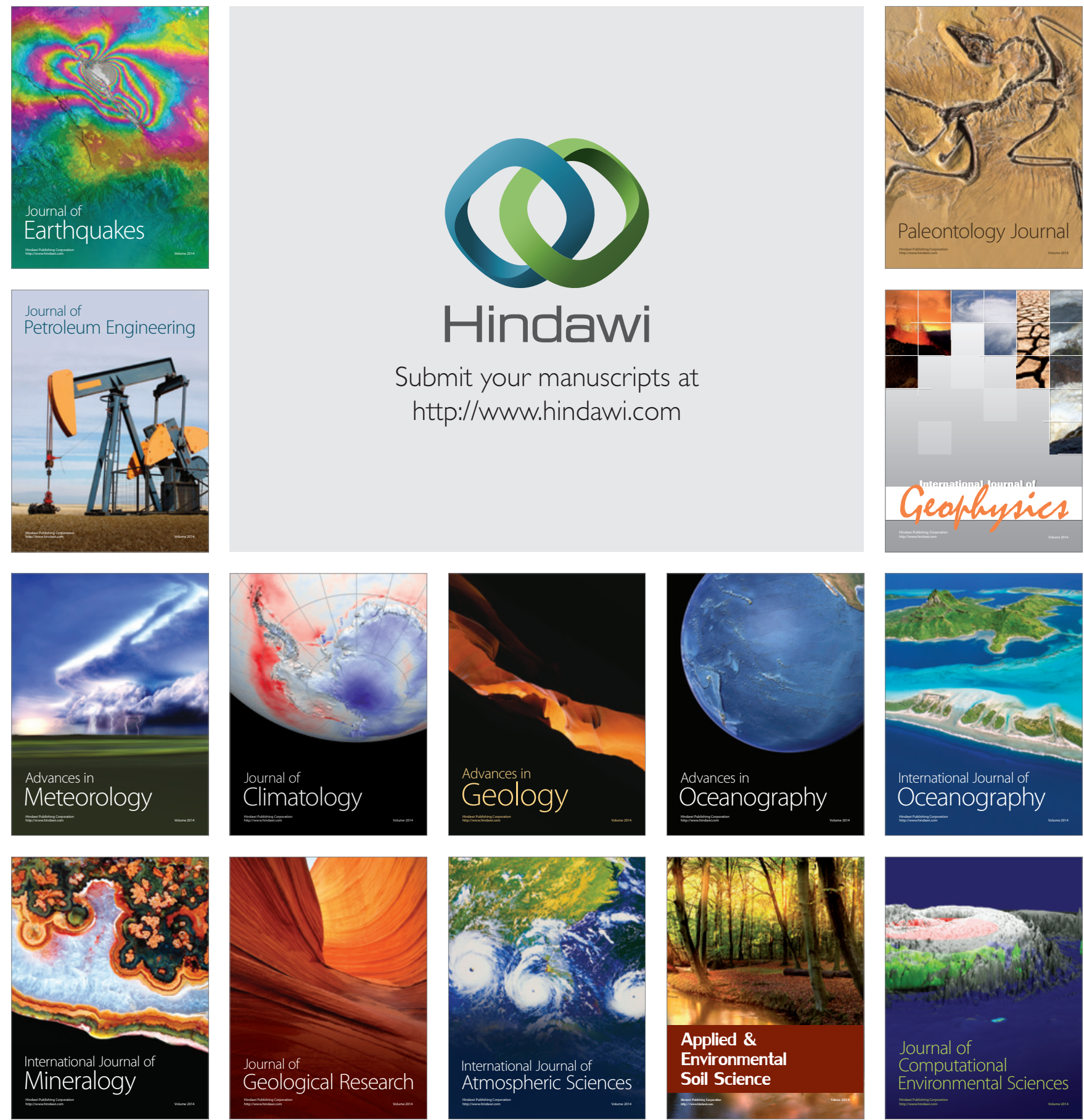